\title{
Cross sectional study of knowledge and awareness among MCH beneficiaries about antenatal and infant care in rural Tamil Nadu, India
}

\author{
Elayarani Elavarasan', Manasi S. Padhyegurjar², Shekhar B. Padhyegurjar ${ }^{3}$ \\ ${ }^{1}$ MBBS, SRM Medical College, Kattankulathur, Kanchipuram, Tamil Nadu, ${ }^{2}$ Professor, Department of Community Medicine, Karpaga Vinayaga \\ Institute of Medical Sciences, Madhurantagam, Kanchipuram, Tamil Nadu, ${ }^{3}$ Professor and Head, Department of Community Medicine, \\ Karpaga Vinayaga Institute of Medical Sciences, Madhurantagam, Kanchipuram, Tamil Nadu. Work attributed to: Department of Community \\ Medicine, SRM Medical College, Kattankulathur, Kanchipuram, Tamil Nadu
}

\section{A B S T R A C T}

\begin{abstract}
Aims and Objectives: Mother and child together form the majority of the population in developing countries. Though they have maximum number of health services attributed to them, morbidity and mortality rates for antenatal women and children are very high. Lack of comprehension of preventive services is one of the important reasons for this. This study was planned with the aim of assessing the knowledge and awareness levels among pregnant women about antenatal care and regarding various aspects of new born and infant care among mothers of under three. Materials and Methods: This is a community based cross- sectional study involving beneficiaries attending the Rural Health Centre of a teaching Medical College, in Tamil Nadu. Results: Awareness about routine antenatal care, danger signs of pregnancy and preparation for emergency labour were observed to be poor among antenatal women. Knowledge about new born care, infant feeding practices, immunization, newborn and childhood illnesses were all found inadequate among mothers of under three. All the aspects were better in antenatal women who were educated, could read Tamil, and belonged to joint family. But these factors had no effect of mothers of under three. Health workers and family members were the major source of information for both the groups. Conclusion: Knowledge is observed to be poor, in spite of all the participants being beneficiaries of Rural Health Centre and the majority of them being educated upto secondary standard. Efficient use of existing health services, giving health education sessions with precise messages will help to increase awareness.
\end{abstract}

Key words: Knowledge, Antenatal care, Infant care, New born care.

\section{INTRODUCTION}

Millennium Development Goals (MDGs) are a set of numerical \& time-bound targets to measure achievements in human and social development laid down by the UN. The $4^{\text {th }}$ goal is to reduce child mortality and the $5^{\text {th }}$ Goal is to improve Maternal Health. These goals are measured by the indicators Infant Mortality Rate (IMR), Under five Mortality Rate, (U5MR) and Maternal Mortality Ratio (MMR). For these MDGs to be achieved by 2015 the national indicators for India need to be 28, 42 and 109 respectively. ${ }^{1}$ In the year 2012, these indicators for India are 42,52and 178 respectively.,3
Although there has been an estimated $4.7 \%$ annual decline in the Maternal Mortality rate, the MMR of India is still at an alarming rate of 178 with the apprehension of not being able to meet the Millennium Development Goals $2015 .{ }^{4}$ Same is the case for IMR and U5MR.

In view of this for a long time our country has been very explicit in promoting and providing a safe motherhood and antenatal care services for the betterment of maternal health as well as that of the infant. However, one of the major determinants for the efficacy of these services is the rate of utilization of these services, which are much lower than the expected specially in the rural areas. ${ }^{5,6}$ 
Awareness of women regarding their health assumes special significance in the Indian context because the maternal health problems are mainly due to ignorance, poverty, and lack of knowledge regarding the issue. It is therefore very important to first focus on services for increasing the awareness level of the mother. ${ }^{7}$ Awareness and knowledge about the rationale behind these services is necessary for escalating the utilization of these services to provide a safe motherhood, delivery and for the well being of the baby. This will in turn decrease the $\mathrm{MCH}$ mortality indicators and help us to achieve the MDGs.

Thus this study was planned with the aim to assess the knowledge and awareness levels among the pregnant women about antenatal care, danger signs during pregnancy \& preparation for emergency labour and to assess knowledge about various aspects of new born care and infant care in mothers with children under three years of age and demographic factors affecting them. This will therefore help in identifying the lacunae in the awareness levels in antenatal care, new born and child care which can be related to the utilisation of these services and hence contribute to bring down the mortality indicators.

\section{MATERIALS AND METHODS}

This is a community based cross- sectional study involving the pregnant women and mothers with children less than 3 years of age. The study was conducted in the field practice area of the Rural Health Centre of a teaching Medical College, located in Kanchipuram District of Tamil Nadu. A list of pregnant women seeking antenatal services and mothers of children under three years of age, who were beneficiaries of the Rural Health Centre was obtained. From the list, 100 antenatal women and 100 mothers of under three were selected by simple random sampling using a table of random numbers.

The questions were prepared with reference to the MotherChild Protection. Mother \& Child Protection card is a comprehensive card providing complete information right from the Antenatal test to growth monitoring of the newly born baby in continuation. This card is prepared by the joint efforts of Health Department and Women \& Child Development Department in collaboration with UNICEF. This card not only gives the information about pregnant women \& child but also give the comprehensive information about the pregnant women, vaccination of child, child nutritional status and prevention of main diseases. ${ }^{8,9}$ The card is also available in local languages. The questionnaire was tested in the field before administration. The questionnaire was orally administered to every individual in the sample after having obtained informed consent. It was administered in the local language (Tamil) by visiting the women in their houses and the given responses were noted accordingly. Verbally administering the questionnaire was aimed at reducing the errors with perception of the questions and to obtain the maximum exact responses. The data was then analysed using SPSS version 16. Proportions were calculated. Single and double tailed $\mathrm{Z}$ tests were appropriately applied and $\mathrm{p}$ values were calculated.

\section{RESULTS}

The mean age of Antenatal women is $24.33 \pm 2.88$ years. $78 \%$ of the participants were educated up to or above secondary section and $82 \%$ could read the local language (Tamil). $51 \%$ belonged to joint family and $49 \%$ belonged to nuclear family.

Average age of mothers of under three in rural area is $25.99 \pm 3.23 .92 \%$ of the mothers were educated upto and above secondary standard and $89 \%$ are able to read Tamil. Fifty-seven percent were from Nuclear families and $43 \%$ from joint families.

Table 1 shows awareness about routine Antenatal care. 69\% women correctly stated that $1^{\text {st }}$ trimester is the ideal time for Antenatal registration, however only 37\% women were aware of minimum three antenatal checkups. Measurement of blood pressure during every visit, 100 Iron Folic Acid tablets and two injections of Tetanus Toxoid were answered correctly by $56 \%, 38 \%$ and $79 \%$ of the sample respectively. Only $23 \%$ of the pregnant women could interpret the family planning symbol correctly. Among the danger signals in pregnancy, pain in abdomen was most commonly perceived $(27.8 \%)$ followed by bleeding (21\%), pedal oedema (13.6\%), convulsions $(10.5 \%)$ and fever (8.6\%). Only $2.5 \%$ women were aware of rupture of membranes and no one perceived pallor as a danger signal. Sixteen percent were not aware of any single danger sign. When asked what preparation would they do in case they suddenly go in labour and an emergency arises, $40.3 \%$ respondents did not know what they would do in such a situation. Thirty-one percent said they would arrange for transport in advance. However only $19.4 \%$ said that they would identify a hospital in advance and only $9.3 \%$ said that they would save money for such a situation.

Table 2, depicts knowledge of mothers of under three on the various aspects of care of infant. The only precautionary measures for new born that the mothers are aware are, initiating breast feeding and providing warmth at birth (23\% and 36\% respectively). Forty-one percent of the samples were not aware of any precautionary measures. 


\begin{tabular}{|c|c|c|}
\hline S. no & $\begin{array}{l}\text { Various aspects of antenatal } \\
\text { care }(n=100)\end{array}$ & $\begin{array}{c}\text { Correct } \\
\text { responses (\%) }\end{array}$ \\
\hline 1 & $\begin{array}{l}\text { Period of antenatal registration } \\
\left(1^{\text {st }} \text { trimester }\right)\end{array}$ & $69(69)$ \\
\hline 2 & $\begin{array}{l}\text { Minimum number of antenatal } \\
\text { checkups ( } 3 \text { times) }\end{array}$ & $37(37)$ \\
\hline 3 & $\begin{array}{l}\text { Number of times BP should be measured } \\
\text { during pregnancy (during every visit) }\end{array}$ & $56(56)$ \\
\hline 4 & $\begin{array}{l}\text { Minimum number of Iron tablets to be } \\
\text { taken during pregnancy ( } 100 \text { tablets) }\end{array}$ & $38(38)$ \\
\hline 5 & $\begin{array}{l}\text { Number of TT injections to be given } \\
\text { during pregnancy ( } 2 \text { injections) }\end{array}$ & $79(79)$ \\
\hline \multirow[t]{2}{*}{6} & $\begin{array}{l}\text { Interpretation of the family planning } \\
\text { symbol }\end{array}$ & $23(23)$ \\
\hline & $\begin{array}{l}\text { Danger signs in pregnancy } \\
{ }^{*} \text { multiple responses }\end{array}$ & \\
\hline 1 & Pain abdomen & $45(27.8)$ \\
\hline 2 & Bleeding & $34(21)$ \\
\hline 3 & Pedal oedema & $22(13.6)$ \\
\hline 4 & Convulsions/unconsciousness & $17(10.5)$ \\
\hline 5 & Fever & $14(8.6)$ \\
\hline 6 & Bursting of bag (rupture of membrane) & $4(2.5)$ \\
\hline 7 & Pallor & $0(0)$ \\
\hline \multirow[t]{2}{*}{8} & Do not know & $26(16)$ \\
\hline & $\begin{array}{l}\text { Preparation for emergency labour } \\
\text { *multiple responses }\end{array}$ & \\
\hline 1 & Arrange for transport & $40(31)$ \\
\hline 2 & Advance identification of hospital & $25(19.4)$ \\
\hline 3 & Save money & $12(9.3)$ \\
\hline 4 & Do not know & $52(40.3)$ \\
\hline
\end{tabular}

Thirty percent of mothers were aware that the new born should not be given bath for the first 7 days. Fever of the new born was perceived as a danger signal by $41 \%$ of the mothers. No cry or continuous cry, not feeding well and yellow palms was considered threat by $18 \%, 11 \%, 9 \%$ respectively. Only $3 \%$ mothers perceived diarrhoea as a risk to new born health. $18 \%$ of the women were not aware of even one danger sign of new born.

Forty-nine point four eight percent mothers were aware that breast feeding is started in the first one hour of birth and $34.02 \%$ knew that exclusive breast feeding should be given for first six months.

Cereals $(42 \%)$ were observed to be the most popular choice of weaning food, followed by pulses (17\%), vegetables $(12 \%)$ and other healthy options like egg, cow's milk etc. (9\%). Fruits were opted by only $1 \%$ of the mothers. Artificial food was preferred by $17 \%$ and biscuits by $2 \%$ of mothers.

$97.89 \%$ mothers were of the opinion that their babies were completely immunized till date. However $62 \%$ were not aware of the name of a single vaccine or supplement given to their child. Very few mothers were aware of the names of the vaccines (BCG 15\%, DPT 10\%, OPV 7\%, Measles 4\% \& Hepatitis B 2\%). Not a single mother knew about Vitamin A.

\section{Table 2: Awareness about infant care}

\begin{tabular}{llc}
\hline S. no & New born care & $\begin{array}{c}\text { Number of } \\
\text { mothers }(\%)\end{array}$ \\
\hline 1 & Precautionary measures for new born & \\
& *multiple responses $(\mathrm{n}=109)$ & $39(36)$ \\
& Breast feeding & $25(23)$ \\
& Providing warmth & 0 \\
& Umbilical cord kept dry & 0 \\
& Kept away from sick & 0 \\
& Check weight of child & $45(41)$ \\
& Do not know & $30(30)$ \\
& 1 & \\
& ( $7^{\text {th }}$ bath of new born after birth) $(n=100)$ &
\end{tabular}

3 Danger signs in new born

*Multiple responses $(n=133)$

Fever/cold to touch

$55(41)$

No cry/continuous crying $23(18)$

Not feeding well $15(11)$

Yellow palms/soles $12(9)$

Diarrhoea/blood in stools $\quad 4(3)$

Convulsions/unconsciousness $0(0)$

Do not know 24 (18)

\begin{tabular}{lll} 
& Do not know & $24(18)$ \\
\hline \multicolumn{3}{c}{ Feeding practices } \\
\hline & $\begin{array}{l}\text { Time of initiation of breast feeding } \\
\text { (within 1 hour) }(\mathrm{n}=97)\end{array}$ & $48(49.48)$ \\
2 & Period of exclusive breast feeding & $33(34.02)$
\end{tabular}

$2 \quad$ Period of exclusive breast feeding 33 (34.02)

$3 \quad$ Food items used for supplementary

feeding after 6 months of exclusive breast

feeding *multiple responses $(n=210)$

Dal (pulses) $\quad 87(42)$

Vegetables $26(12)$

Fruits $3(1)$

Other healthy food options(egg, cow milk) 17 (9)

Artificial food (cerelac/lactogen) $36(17)$

Biscuits

$5(2)$

\begin{tabular}{|c|c|c|}
\hline & Immunization & \\
\hline 1 & $\begin{array}{l}\text { Mothers perception of complete } \\
\text { immunization (complete) }\end{array}$ & $93(97.89)$ \\
\hline \multirow[t]{9}{*}{2} & $\begin{array}{l}\text { Name of vaccines/supplements known } \\
\text { *multiple responses }(n=122)\end{array}$ & \\
\hline & BCG & $18(15)$ \\
\hline & DPT & $12(10)$ \\
\hline & OPV & $9(7)$ \\
\hline & Measles & $5(4)$ \\
\hline & Hepatitis B & $2(2)$ \\
\hline & Vitamin A & $0(0)$ \\
\hline & Do not know & $76(62)$ \\
\hline & Growth and Development & \\
\hline \multirow[t]{2}{*}{1} & Ideal shape of normal growth curve $(n=100)$ & $42(42)$ \\
\hline & Important childhood illnesses & \\
\hline \multirow[t]{6}{*}{1} & $\begin{array}{l}\text { Common childhood illnesses } \\
{ }^{*} \text { multiple responses }(n=218)\end{array}$ & \\
\hline & Fever & $91(42)$ \\
\hline & Respiratory infections & $63(29)$ \\
\hline & Diarrhoea & $42(19)$ \\
\hline & Others (Jaundice, polio) & $18(8)$ \\
\hline & Do not know & $4(2)$ \\
\hline \multirow[t]{7}{*}{2} & $\begin{array}{l}\text { Treatment of diarrhoea at home } \\
\text { *multiple responses }(n=101)\end{array}$ & \\
\hline & ORS & $17(17)$ \\
\hline & Extra fluids & $13(13)$ \\
\hline & Continue normal diet & $5(5)$ \\
\hline & Continue breast feeding & $2(2)$ \\
\hline & Hospitalization & $42(42)$ \\
\hline & Do not know & $22(21)$ \\
\hline
\end{tabular}


Forty-two percent mothers could correctly tell about the ideal shape of a growth curve (upward). Forty-two percent women identified fever as an important childhood illness, followed by respiratory infections $(29 \%)$. Nineteen percent mothers identified diarrhoea as a common illness. However 21\% did not know how to treat diarrhoea at home. Seventeen percent knew about ORS and 13\% about extra fluids. Only $2 \%$ thought that breast feeding should be continued and $5 \%$ were of the opinion that normal diet should be continued. Forty-two percent of the sample regarded hospitalization necessary for management of a child with diarrhoea.

On the basis of correct responses, individual scores in different categories were calculated followed by calculation of average scores in percentages. The average scores were then compared with the demographic factors like education of the women, ability to read Tamil and type of family. Standard deviation and Z-tests were applied. Table 3 shows the demographic factors affecting the scores. It is observed that antenatal women educated more than $10^{\text {th }}$ standard, those who could read Tamil and those belonging to joint families scored significantly better. However the same factors have not affected the scores of mothers of children under three years of age.

Figure 1 shows various sources of information mentioned by both the groups of beneficiaries. Health Workers and Family members are a major source of information for both the group. Past experience plays a more important role in antenatal group and $\mathrm{MCH}$ card in infant care. Peers play a small role in awareness and contribution of media is very poor in both the groups.

\section{DISCUSSION}

Awareness about registration in the first trimester and minimum two T'T injections and BP measurement during every visit was observed in more than fifty per cent of the population $(69 \%, 79 \%$ and $56 \%$ respectively). Awareness about minimum three check-ups and 100 Iron Folic Acid tablets was found to be very low (37\% and $38 \%$ respectively). Only $23 \%$ of people were aware of the family planning symbol. This is correctly reflected in national statistics. As per NFHS 3 only $50.7 \%$ antenatal cases completed three antenatal visits and only $22.3 \%$ consumed 90 IFA tablets in rural India. ${ }^{10}$ The findings of knowledge about ANC care in the current study are better than a similar study conducted in urban area of Imphal. ${ }^{11}$ In an ICMR task force study, conducted in 28 districts in rural India, awareness about ANC registration was found to be low, but regarding TT injections and IFA tablets, high levels of awareness was observed among those who were

\begin{tabular}{|c|c|c|c|c|}
\hline $\begin{array}{l}\text { Demographic } \\
\text { variables }\end{array}$ & $\begin{array}{c}\text { Sample } \\
\text { size }\end{array}$ & $\begin{array}{l}\text { Average } \\
\text { score (\%) }\end{array}$ & $\begin{array}{l}\text { Standard } \\
\text { deviation }\end{array}$ & $\begin{array}{c}\text { Test of } \\
\text { significance }\end{array}$ \\
\hline \multicolumn{5}{|l|}{ Education } \\
\hline \multicolumn{5}{|l|}{ Antenatal care } \\
\hline$\leq 10^{\text {th }}$ standard & 79 & 30.23 & 13.18 & $Z=4.33$ \\
\hline$>10^{\text {th }}$ standard & 21 & 46.21 & 20.74 & $\begin{array}{l}\mathrm{P}=0.001^{* *}, \\
\text { double tailed }\end{array}$ \\
\hline \multicolumn{5}{|l|}{ Infant care } \\
\hline$\leq 10^{\text {th }}$ standard & 75 & 22.22 & 6.85 & $Z=1.69$ \\
\hline$>10^{\text {th }}$ standard & 25 & 24.89 & 6.94 & $\begin{array}{c}P=0.0455 \\
\text { single tailed }\end{array}$ \\
\hline \multicolumn{5}{|l|}{ Ability to read tamil } \\
\hline \multicolumn{5}{|l|}{ Antenatal care } \\
\hline Read Tamil & 82 & 35.22 & 17.23 & $\mathrm{Z}=2.18$ \\
\hline $\begin{array}{l}\text { Can't read } \\
\text { Tamil }\end{array}$ & 18 & 26.14 & 8.13 & $\begin{array}{c}\mathrm{P}=0.03^{*}, \\
\text { double tailed }\end{array}$ \\
\hline \multicolumn{5}{|l|}{ Infant care } \\
\hline Read Tamil & 89 & 23.19 & 7.02 & $Z=1.26$ \\
\hline $\begin{array}{l}\text { Can't read } \\
\text { Tamil }\end{array}$ & 11 & 20.39 & 5.92 & $\begin{array}{c}\mathrm{P}=0.21, \\
\text { double tailed }\end{array}$ \\
\hline \multicolumn{5}{|l|}{ Type of family } \\
\hline \multicolumn{5}{|l|}{ Antenatal care } \\
\hline Nuclear & 49 & 30.85 & 14.73 & $Z=1.66$ \\
\hline Joint & 51 & 36.22 & 17.46 & $\begin{array}{l}\mathrm{P}=00.0485^{*}, \\
\text { single tailed }\end{array}$ \\
\hline \multicolumn{5}{|l|}{ Infant care } \\
\hline Nuclear & 57 & 23.01 & 7.35 & $Z=0.23$ \\
\hline Joint & 43 & 22.69 & 6.42 & $\begin{array}{c}\mathrm{P}=0.82 \\
\text { double tailed }\end{array}$ \\
\hline
\end{tabular}

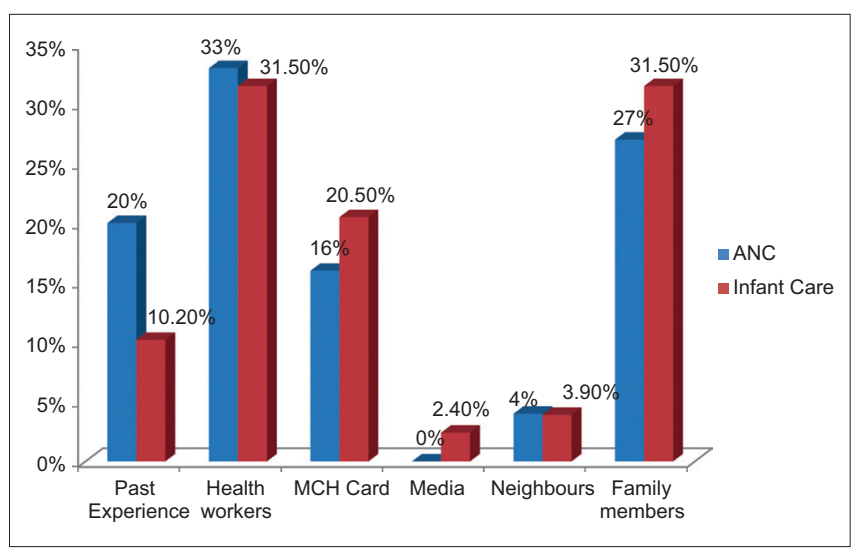

Figure 1: Source of Information

availing ANC services. ${ }^{5}$ Mahajan and Sharma observed in their study that knowledge about IFA tablets and TT injections were low in both urban as well as rural population in Maharashtra. ${ }^{7}$

Knowledge of danger signs of obstetric complications during pregnancy, labor and postnatal period is the first essential step for appropriate and timely referral. ${ }^{12}$ However in the present study, awareness about most of the danger signals of pregnancy and the preparation need to be done for emergency labour was found to be extremely poor with $16 \%$ antenatal women not knowing a single danger sign. In a study conducted in Rural Tanzania $42 \%$ of clients 
were not aware of any danger signs. ${ }^{13}$ Several studies show poor awareness of danger signs of pregnancy. ${ }^{5,12}$ Women educated above $10^{\text {th }}$ standard, those who could read Tamil and those from joint family, had significantly better average scores. Similar results were observed by M.N.Haque in a study conducted in Bangladesh. ${ }^{14}$

Knowledge about infant care was observed to be very low in all aspects. Providing warmth to the newborn and immediate breast feeding were the only precautionary measures that the mothers were aware of. Maintaining the normal body temperature is extremely important in newborns because of their larger body surface area. A study done in rural India has proven that even when pregnant mothers who have access to a trained birth attendant for delivery at home, thermal care is the component of essential newborn care which gets neglected. ${ }^{15}$

It is a very common practice in India to bathe the newborns immediately after birth. This puts the newborn at risk of hypothermia which gets worse with the lack of adequate drying and warm clothes. The reason for this practice is the belief that the blood/fluid/vernix which stays on new-born's skin after birth is impure and has to be removed thoroughly. In the study conducted by Padiyath MA etal., more than $75 \%$ of mothers said that the first bath should be given after the $1^{\text {st }}$ day of birth. ${ }^{16}$ In the current study, only $30 \%$ women were aware that the new born should not be bathed for first 7 days. These findings are better than study conducted by Gupta P et al., in which only $15.1 \%$ said that baby should not be bathed and only dry up with a clean cloth. ${ }^{17}$

Fever was the most commonly known danger sign (41\%) and $18 \%$ not being aware of any danger sign in new born. Though 49.48\% women knew that breast feeding should be initiated in first hour of birth, only $34.02 \%$ could correctly tell the period of exclusive breast feeding. Healthy food options like cereals and pulses were preferred over formula food and biscuits. Multiple studies have got findings better than the current study regarding initiating breast feeding in half an hour, and exclusive breast feeding. ${ }^{18,19}$ Lower results were observed in a study conducted in Uttar Pradesh. ${ }^{17}$

Globally in 2010, approximately 50\% of the 19.3 million infants who were not fully vaccinated lived in India, Nigeria and the Democratic Republic of Congo (DRC). ${ }^{20}$ Though majority of mothers $(97.89 \%)$ felt that their babies were completely immunized awareness regarding the name of the vaccines is very poor. None of the mothers were aware about Vitamin A. Inadequate knowledge on immunization has been observed in multiple studies. ${ }^{16,21}$

Growth charts are important tools for monitoring child growth. In a study conducted by Okafor IP et al., it is mentioned that parents and caregivers lack knowledge and understanding of growth charts and this may limit their benefits as educational tools by healthcare providers. Unfortunately, in both rural and urban areas, there is low usage of growth charts in health facilities. ${ }^{22}$ Even in the current study, only $42 \%$ mothers cold correctly identify the ideal shape of the growth curve.

Delay in seeking appropriate healthcare for sick children can potentially result in mortality especially in developing countries. ${ }^{22}$ Thus timely identification of a sick child by the mother is very important for timely referral. In this study fever was the most commonly known childhood illness followed by respiratory infections and diarrhoea. Similarly, difficulty in breathing was most commonly identified health issue followed by others in a study conducted in Wardha. ${ }^{23}$

Majority of the respondents felt that hospitalization was indicated in the case of diarrhoea and very few knew about ORS and extra fluids. Even in NFHS 3 it is observed that $61.5 \%$ childhood diarrhoea cases were taken to health facility and only $26.2 \%$ received ORS. ${ }^{10}$

In a study conducted by Sinha AK and Srivastava SP, it is observed that generally parents thought anti-diarrheal drugs are must for treatment and knowledge regarding ORS and its use in diarrhoea and vomiting was very poor. ${ }^{24}$ In the current study, $2 \%$ of the mothers were of the opinion that breast feeding should be continued during diarrhoea. Better results were observed in other studies. ${ }^{19}$

Education, ability to read Tamil and joint family had positive effect on scores of Antenatal women. However they had no effect on scores of mothers. Similarly, all aspects were poorly known among illiterates in a study conducted in Bihar. ${ }^{24}$

Health workers and family members play a major role in providing information for both the groups. MCH card though very precise and informative is not found to be very popular in spreading awareness. Media has been found to be ineffective in spreading awareness. Even the family planning symbol was identified by only $23 \%$ of the antenatal women. Other studies have mentioned anganwadi worker and health facilities as main source of information on mother and child care. ${ }^{21,18}$

\section{CONCLUSION}

All key Indicators of India for Maternal and Child health in NFHS - 3 are very poor especially for rural India. All indicators of rural TN, though low are better than their National counterparts. ${ }^{25}$ Inspite of this it is observed that knowledge and awareness about the various aspects of 
antenatal, newborn and infant care is very poor. This is despite all the participants being beneficiaries of Rural Health Centre and the majority of them being literate and educated upto secondary standard. If we want beneficiaries to accept our services, make use of them, which will eventually lead to decrease in our mortality and morbidity indicators, we should provide them with a clear understanding of the reason or scientific rationale of why a particular intervention is essential. The literacy rates of both the study groups are good. Local language is also understood well by the population. This fact can be used to our advantage in creating awareness. It is observed that Health workers are the major source of information. This fact can be used to spread more effective information. Use of $\mathrm{MCH}$ card should be increased, also role of media needs to be improved. Thus making use of existing infrastructure and staff we need to devise targeted health education sessions using existing IEC material like the MCH card more effectively. Efficient use of existing assets, giving precise information on the topics, will help us to increase awareness, which in turn will increase utilization of services and help to achieve the targets of MDGs.

\section{ACKNOWLEDGEMENT}

This study has been awarded the prestigious ICMR - Short Tern Studentship (STS).We are thankful to the Head of the Department and staff of Department of Community Medicine and the Rural Health Centre, SRM Medical College, for their help in carrying out the study.

\section{REFERENCES}

1. Govt. of India, Maternal \& Child Mortality and Total Fertility Rates, Sample Registration System (SRS), Office of Registrar General.[online] 2011 [cited 2014July 28]. Available from: URL: http://censusindia.gov.in/vital_statistics/SRS_Bulletins/MMR_ release_070711.pdf.

2. Govt. of India, Figures at a glance, India - 2012, Sample Registration System (SRS), Office of Registrar General. [online] 2012 [cited 2014 July 29]. Available from: URL: http://www. censusindia.gov.in/vital_statistics/SRS_Report_2012/2_At_a_ glance_2012.pdf.

3. Govt. of India, Special Bulletin on Maternal Mortality in India 2010 - 12,Sample Registration System (SRS), Office of Registrar General. [online] 2013 [cited 2014 July 28]. Available from: URL: http://www.censusindia.gov.in/vital_statistics/SRS_ Bulletins/MMR_Bulletin-2010-12.pdf.

4. Montgomery AL, Ram U, Kumar R and Jha P. For The Million Death Study Collaborators (2014) Maternal Mortality in India: Causes and Healthcare Service Use Based on a Nationally Representative Survey. PLoS ONE2014; 9(1): e83331. doi:10.1371/journal.pone.0083331.

5. Chandhiok N, Dhillon BS, Kambo I and Saxena NC. Determinants of antenatal care utilization in rural areas of India: Acrosssectional study from 28 districts (An ICMR task force study).J ObstetGynecol India 2006; 56(1):47-52.
6. Roy MP, Mohan U, Singh SK, Singh VK and Srivastava AK. Determinants of Utilization of Antenatal Care Services in Rural Lucknow. India J Family Med Prim Care 2013; 2(1): 55-59.

7. Mahajan $\mathrm{H}$ and Sharma B. Utilization of Maternal and Child Health Care Services byPrimigravida Females in Urban and Rural Areas of India. ISRN Preventive Medicine [online] 2014[cited 2014 July 12]. Available from: URL: http://www. hindawi.com/journals/isrn.preventive.medicine/2014/123918.

8. Innovative Schemes and Programme Interventions under NRHM. Government of Madhya Pradesh, Department Of Public Health \& Family Welfare, Bhopal. [online] [cited 2014 July 20]. Available from: URL: http://www.health.mp.gov.in/nrhm/ Innovative-nrhm.pdf.

9. A guide for use of the mother-child protection card for the community and the family, AWW, ANM \& sector supervisors. GOI\& UNICEF. [online] [cited 2014 July 20]. Available from: URL: http://hetv.org/pdf/protection-card/mcp-english.pdf.

10. Key Indicators for India from National Family Health Survey (NFHS-3), India 2005-06, International Institute of Population Sciences, Mumbai India. [online] [cited 2014 July 25]. Available from: URL: http://www.rchiips.org/nfhs/pdf/India.pdf.

11. Laishram J, ThounaojamUd, PanmeiJ,Mukhia S and Sanayaima Devi $\mathrm{H}$. Knowledge and practice of ante-natal care in an urban area. Indian Medical Gazette 2013; 101-106.

12. Hailu M, Gebremariam A and Alemseged F. Knowledge about obstetric danger signs among pregnant women in Aleta Wondo District, Sidama Zone,Southern Ethiopia. Ethiop J Health Sci 2010; 20(1):25-32.

13. Pembe AB, CarlstedtA,UrassaDP,Lindmark G,NyströmL and Darj E. Quality of antenatal care in rural Tanzania: Counselling on pregnancy danger signs.BMC Pregnancy Childbirth 2010; 10: 35.

14. Haque MN. Individual's Characteristics Affecting Maternal Health Services Utilization: Married Adolescents And Their Use Of Maternal Health Services In Bangladesh. The Internet Journal of Health 2009;8(2)[online] [cited 2014 July 11]. Available from: URL: http://ispub.com/lJH/8/2/10489.

15. Baqui AH, Williams EK, Darmstadt GL, Kumar V, Kiran TU, Panwar D, et al. Newborn Care in Rural Uttar Pradesh, Indian J Pediatr 2007; 74; 241-247.

16. Padiyath MA, Bhat VB and Ekambaram M. Knowledge attitude and practice of neonatal care among postnatal mothers.Curr Pediatr Res 2010; 14 (2): 147-152.

17. Gupta P, Srivastava VK, Kumar V, Jain S, Masood J, Ahmad N, et al. Newborn care practices in urban slums of Lucknow city, UP. Indian J Community Med 2010; 35 (1):82-85.

18. Petit Al. Perception and Knowledge on Exclusive Breastfeeding among Women attending Antenatal and Postnatal Clinics. A Study from Mbarara Hospital - Uganda, August 2008. Official Publication of the Tanzania Medical Students' Association 2010; 16(1) 27-30.

19. Dhandapany G, Bethou A, Arunagirinathan A and Ananthakrishnan S. Antenatal counseling on breastfeeding is it adequate? A descriptive study from Pondicherry, India. International Breastfeeding Journal 2008,3:5.[online] [cited 2014 July 17].Available from: URL: http://www. internationalbreastfeedingjournal.com/content/3/1/5.

20. World Health Organization: Weekly Epidemiological Record. No. 46, 2011, 86, 509-520. [online] [cited 2014 July 21]. Available from: URL: http://www.who.int/wer/2011/wer8646.pdf.

21. Mahalingam S, Soori A, Ram P, Achappa B, Chowta M and Madi D. Knowledge, attitude and perceptions of mothers with children under five years of age about vaccination in Mangalore, India. Asian Journal of Medical Sciences 2014; 5(4): 52-57.

22. Okafor IP, Dolapo DC, Onigbogi MO and Iloabuchi IG.Rural- 
urban disparities in maternal immunization knowledge and childhood health-seeking behavior in Nigeria: A mixed method study. African Health Sciences 2014; 14(2):339-347.

23. Dongre AR, Deshmukh PR and Garg BS. Awareness and health care seeking for newborn danger signs among mothers in periurban Wardha. Indian J Pediatr 2009; 76(7):691-693.

24. Sinha AK and Srivastava SP. Awareness of diarrheal disease control in rural and urban areas of Bihar. Indian Pediatr 1993; 30(12):1433-1439.

25. Key Indicators for Tamil Nadu from National Family Health Survey (NFHS-3), India 2005-06, International Institute of Population Sciences, Mumbai India. [online] [cited 2014 July 20]. Available from: URL: http://www.rchiips.org/nfhs/pdf/Tamil\%20 Nadu.pdf.

\section{Authors Contribution:}

EE - Concept and design of the study, reviewed the literature, collected data, manuscript preparation. MSP - Concept and design of the study, reviewed

the literature, helped in preparing first draft of manuscript, critical revision of the manuscript. SBP - Helped in designing the study, statistically analyzed and

interpreted the data, critical revision of the manuscript.

Source of Support: Nil, Conflict of Interest: None declared. 